\title{
Paraganglioma of the bladder in a kidney transplant recipient: A case report
}

\author{
HÉLÈNE LAZARETH ${ }^{1}$, DANIEL COHEN ${ }^{2}$, VIOREL VASILIU ${ }^{3}$, CLAIRE TINEL $^{1}$, \\ FRANK MARTINEZ ${ }^{1}$, JEAN-PIERRE GRÜNFELD ${ }^{1}$, MARIE-FRANCE MAMZER ${ }^{4}$, \\ CHRISTOPHE LEGENDRE ${ }^{1}$ and REBECCA SBERRO-SOUSSAN ${ }^{1}$
}

\author{
${ }^{1}$ Department of Nephrology and Kidney Transplantation, Necker Enfants-Malades Hospital, Paris Descartes University; \\ ${ }^{2}$ Department of Urology, Georges Pompidou European Hospital; ${ }^{3}$ Department of Pathology, Necker Enfants-Malades Hospital \\ and ${ }^{4}$ Department of Medical Ethics and Legal Medicine, Paris Descartes University, \\ Assistance Publique-Hôpitaux de Paris, 75015 Paris, France
}

Received November 3, 2016; Accepted January 30, 2017

DOI: $10.3892 / \mathrm{mco} .2017 .1182$

\begin{abstract}
Renal transplantation has been associated with a significantly increased risk of developing cancer, including bladder neoplasia, with urothelial carcinoma being the most frequent type of bladder cancer. Bladder paraganglioma, also referred to as extra-adrenal pheochromocytoma, is a rare but severe condition that may cause a severe hypertensive crisis during handling and mobilization of the tumor. We herein present the case of a 67-year-old kidney transplant recipient with a bladder polyp consistent with paraganglioma of the bladder. During bladder polyp resection, the patient developed severe hypertension, which resolved with appropriate treatment. The histological analysis of the resected bladder polyp was consistent with extra-adrenal pheochromocytoma, or paraganglioma, and the patient finally underwent partial cystectomy, with no reported postoperative recurrence. To the best of our knowledge, this is the first report of a case of paraganglioma of the bladder in a kidney tranplant recipient. Total or partial bladder cystectomy is considered to be an effective treatment for this type of bladder tumor. Screening for mutations of the succinate dehydrogenase subunit B gene may also be recommended.
\end{abstract}

\section{Introduction}

Renal transplantation has been associated with a significantly increased risk of developing cancers during long-term follow-up. A recent meta-analysis identified a 3.18-fold higher

Correspondence to: Dr Hélène Lazareth, Department of Nephrology and Kidney Transplantation, Necker-Enfants Malades Hospital, Paris Descartes University, Assistance Publique-Hôpitaux de Paris, 147 Rue de Sèvres, 75015 Paris, France

E-mail: helene.lazareth@gmail.com

Key words: hypertension, kidney transplantation, paraganglioma, pheochromocytoma, urinary bladder standardised incidence for bladder cancer in kidney transplant recipients compared with the general population (1). The underlying mechanisms are multiple, including cellular damage by immunosuppressive therapy, i.e., cyclophosphamide therapy or viral factors, such as BK virus infection (2). The histological findings are mostly consistent with urothelial carcinoma (3).

Paragangliomas, also referred to as extra-adrenal pheochromocytomas, originate from mature chromaffin cells located along the para-aortic and paravertebral axis (4). The urinary bladder is the third most frequent primary site $(11 \%)$, after the organ of Zuckerkandl $(53 \%)$ and the adrenal glands $(26 \%)$, followed by the mediastinum (5\%) and the neck (5\%) (5). The majority of bladder paragangliomas are solitary, arising on the dome or on the trigone.

We herein report the case of a kidney transplant recipient with a bladder polyp consistent with paraganglioma of the bladder. To the best of our knowledge, this is the first report of a case of paraganglioma of the bladder in a kidney tranplant recipient.

\section{Case report}

A 67-year-old woman was admitted to the Necker Hospital in April, 2013, for bladder polyp resection 2 years after renal transplantation. The patient had been dialyzed for 33 years for chronic tubulointerstitial nephritis and had a history of endometrial carcinoma treated by complete hysterectomy in 1990; she was also treated for left adrenal pheochromocytoma by left radical nephrectomy in 1991 . The patient had been a smoker (20 pack-years) but had quit 20 years prior to the kidney transplantation. The main complaints on admission were general fatigue and weight loss; based on these symptoms, abdominal computed tomography (CT) and magnetic resonance imaging (MRI) examinations were performed and revealed a bladder polyp (Fig. 1). There was no hematuria or dysuria. The blood and urinary tests were unremarkable (creatinine: $1.6 \mathrm{mg} / \mathrm{dl}$, normal range: $0.4-1.1 \mathrm{mg} / \mathrm{dl}$; and C-reactive protein: $6 \mathrm{mg} / \mathrm{dl}$, normal range: $0-10 \mathrm{mg} / \mathrm{dl})$. The treatment included prednisone $6 \mathrm{mg} /$ day, azathioprine $75 \mathrm{mg} /$ day, tacrolimus $5 \mathrm{mg} /$ day, furosemide $60 \mathrm{mg} /$ day and atenolol $100 \mathrm{mg} / \mathrm{day}$. 


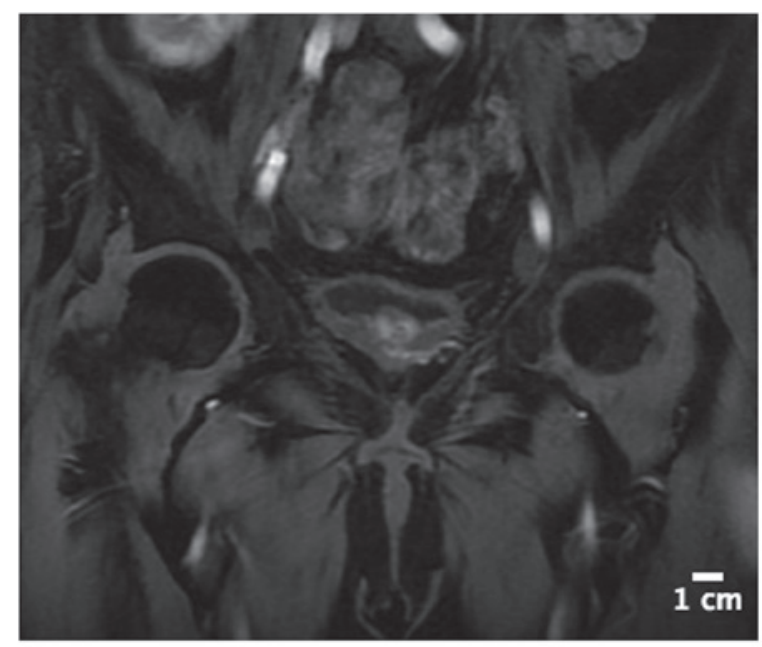

Figure 1. Pelvic magnetic resonance imaging showing a lesion of the bladder trigone sized 16x11x16 mm, exhibiting contrast uptake, without locoregional dissemination.
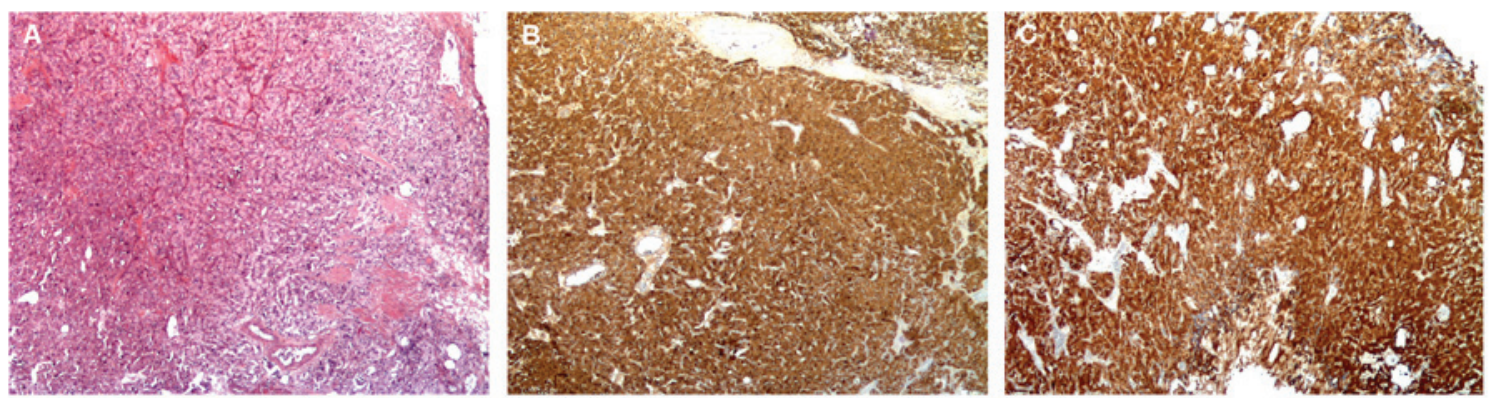

Figure 2. Histological examination of the resected vesical polyp revealed (A) nested proliferation of cells with abundant eosinophilic and granular cytoplasm (hematoxylin and eosin staining) and homogenous immunoreactivity with neuroendocrine markers such as (B) chromogranin A and (C) synaptophysin (magnification, $\mathrm{x} 10$ ).

During bladder polyp resection, the patient developed severe hypertension $(240 / 110 \mathrm{mmHg})$ and flush associated with flash pulmonary edema and acute coronary syndrome (serum troponin: $2.53 \mathrm{ng} / \mathrm{ml}$, normal range: $<0.04 \mathrm{ng} / \mathrm{ml}$ ), which resolved with diuretics, heparin and antiplatelet treatment in association with antihypertensive drugs (alpha- and beta-blockers).

The histological analysis of the resected bladder polyp was consistent with extra-adrenal pheochromocytoma, or paraganglioma (Fig. 2). The patient was asymptomatic and reported no hypertension, malaise or thunderclap headache after voiding.

The urinary excretion of normetanephrine $(286 \mathrm{nmol} / \mathrm{mmol}$ creatininuria; normal, $<280 \mathrm{nmol} / \mathrm{mmol}$ creatininuria) was marginally increased, but that of metanephrine was not (109 nmol/mmol creatininuria; normal, <200 nmol/mmol creatininuria). Bladder MRI revealed a lesion in the bladder trigone, sized 16x11 x16 mm, exhibiting contrast uptake without locoregional dissemination. A positron emission tomography (PET) /CT scan using ${ }^{18} \mathrm{~F}$-dihydroxyphenylalanine (F-DOPA) revealed no metastatic dissemination. The patient finally underwent partial cystectomy. On the last follow-up visit (January, 2017) there was no postoperative recurrence in the absence of any additional treatment.

\section{Discussion}

Paragangliomas, also referred to as extra-adrenal pheochromocytomas, are often benign and non-functional tumors, i.e., there is no secretion of metanephrine and/or catecholamine (6). Paragangliomas of the urinary bladder are rare. The first case of bladder pheochromocytoma was reported in 1953 by Zimmerman et al (7). From this date onwards, $>185$ cases have been reported in the literature to date (6).

Bladder paragangliomas represent $9.8 \%$ of all extra-adrenal paragangliomas and only account for $0.06 \%$ of all primary urinary bladder tumors. Urinary bladder paragangliomas predominantly affect women, with a mean age of 45 years, and are usually located intramurally in the lateral and posterior walls and the trigone of the bladder, with a mean size of $1.9 \mathrm{~cm}(8)$.

The clinical symptoms are usually associated with micturition, and they may include hematuria, flush, paroxysmal hypertension, headache, palpitations or blurred vision during or after voiding (8).

Diagnosis is based on the correlation of clinical symptoms, biological results (such as elevation of urinary catecholamines), specific localizations with F-DOPA uptake on PET/CT and histological findings (including immunohistochemical staining with neuroendocrine markers). A 
proportion of pheochromocytomas are clinically silent and, in the majority of those cases, the levels of catecholamines and their metabolites in the blood and urine are found to be normal (9).

Malignancy is estimated at a rate of 5-15\% (9). Genetic studies have recently established the importance of various mutations in the progression of paragangliomas to malignancy. The association of succinate dehydrogenase subunit $\mathrm{B}$ gene mutations with pelvic paragangliomas is frequently reported (10).

These tumors are characterized by symptom recurrence with tumor mobilization. Cystoscopy under local anesthesia may cause a hypertensive crisis due to bladder filling and should be deferred whenever this diagnosis is considered.

The definitive treatment is surgical and consists of partial cystectomy. Radiotherapy by either ${ }^{131}$ I-MIBG or the radioactive somatostatin analogue ${ }^{177} \mathrm{Lu}$-octreotate and chemotherapy may be used in cases of metastasis dissemination (6).

To the best of our knowledge, this is the first case of pheochromocytoma recurrence or multiple pheochromocytoma in a kidney transplant recipient. Paraganglioma of the urinary bladder is a rare occurrence, but it should be considered if tumor resection is associated with a hypertensive crisis. This type of surgery is associated with a high risk of hemodynamic failure and should be performed with intensive care unit support.

\section{References}

1. Yan L, Chen P, Chen EZ, Gu A and Jiang ZY: Risk of bladder cancer in renal transplant recipients: A meta-analysis. Br J Cancer 110: 1871-1877, 2014.
2. Alexiev BA, Randhawa P, Vazquez Martul E, Zeng G, Luo C, Ramos E, Drachenberg CB and Papadimitriou JC: BK virus-associated urinary bladder carcinoma in transplant recipients: Report of 2 cases, review of the literature, and proposed pathogenetic model. Hum Pathol 44: 908-917, 2013.

3. Prabharasuth D, Moses KA, Bernstein M, Dalbagni G and Herr HW: Management of bladder cancer after renal transplantation. Urology 81: 813-819, 2013.

4. Edström E, Mahlamäki E, Nord B, Kjellman M, Karhu R, Höög A, Goncharov N, Teh BT, Bäckdahl M and Larsson C: Comparative genomic hybridization reveals frequent losses of chromosomes $1 \mathrm{p}$ and $3 \mathrm{q}$ in pheochromocytomas and abdominal paragangliomas, suggesting a common genetic etiology. Am J Pathol 156: 651-659, 2000.

5. Madani R, Al-Hashmi M, Bliss R and Lennard TWJ: Ectopic pheochromocytoma: Does the rule of tens apply? World J Surg 32: 334, 2008.

6. Beilan JA, Lawton A, Hajdenberg J and Rosser CJ: Pheochromocytoma of the urinary bladder: A systematic review of the contemporary literature. BMC Urol 13: 22, 2013.

7. Zimmerman IJ, Biron RE and Macmahon HE: Pheochromocytoma of the urinary bladder. N Engl J Med 249: 25-26, 1953.

8. Schaefer IM, Gunawan B, Füzesi L, Blech M, Frasunek J and Loertzer H: Chromosomal imbalances in urinary bladder paraganglioma. Cancer Genet Cytogenet 203: 341-344, 2010.

9. Doran F, Varinli S, Bayazit Y, Bal N and Ozdemir S: Pheochromocytoma of the urinary bladder. APMIS 110: 733-736, 2002.

10. Burnichon N, Rohmer V, Amar L, Herman P, Leboulleux S, Darrouzet V, Niccoli P, Gaillard D, Chabrier G, Chabolle F, et al: The succinate dehydrogenase genetic testing in a large prospective series of patients with paragangliomas. J Clin Endocrinol Metab 94: 2817-2827, 2009. 